\title{
Viscosity Studies on Gum Karaya
}

\author{
Rao V. Malladi ${ }^{1}$, A. Radha Gayathri ${ }^{2}$ \\ ${ }^{1,2}$ Dr. Rao’s Laboratories, 2-130, P\&T Colony, Ramavarappadu, Vijayawada- 521108, Andhra Pradesh, India
}

\begin{abstract}
The present paper deals with viscosity studies on Gum Karaya. Initial studies on Gum Karaya samples stored for about a year showed low viscosity of about 25 cps. Gum Karaya samples of all the three grades I, II, and III showed the same viscosity pattern. Since viscosity is a very important factor in determining the quality of the product, studies were extended to various samples of different periods of storage. The viscosity was found to be as much as 1800 cps for freshly procured and dried gum to about 25 cps for the gum on prolonged storage. It is observed that the viscosity drops down substantially with aging of Gum Karaya making it unusable for desired applications. Since viscosity is an essential factor for products like denture adhesives and colostomy appliances it is desirable that the Gum Karaya should be as fresh as possible for these applications.
\end{abstract}

Keywords: Gums, Karaya, Sterculia, colostomy, viscosity, food, additive, denture, polysaccharide, laxative

\section{Introduction}

Karaya gum also known as Indian tragacanth is the dried exudate of the trees Sterculia $s p$. The genus Sterculia comprises about 100 species [1] of which approximately 25 species are reported in tropical forests of South Africa [2]. The tree Sterculia urens is common in India in the tropical deciduous forests mostly in dry and rocky areas. Major areas producing Gum Karaya in India are Tropical Himalayas, West and Central India, Deccan Plateau and throughout the Eastern and Western ghats[3].The fully mature tree attains a height of more than 30 feet in forest areas with a significant smooth greenish-grey bark or white bark peeling off [4].

Gum Karaya is a polysaccharide of high molecular weight which on hydrolysis yields D-galactose, L-rhamnose, and Dgalacturonic acid, together with minor amounts of Dglucuronic acid [5]. A significant feature of Gum Karaya is the presence of acetic acid in the polysaccharide.

The gum is procured from the tree by physically injuring the tree by blazing with a knife and collecting the exudate. The collected gum may be dried exudate on the tree or wet mass which is subsequently air dried. The dried Gum Karaya appears as hard lumps.

Gum Karaya in the raw form is commercially available in three grades Grade I, II and III. The essential difference between these grades is the appearance and percentage of Bark and Foreign Organic Matter (B.F.O.M). The Bureau of Indian Standards laid down the following specifications as presented in table 1 (IS:5025-1969) on gum grading [5].

Table 1: Grades of Gum Karaya

\begin{tabular}{|c|c|c|}
\hline Grade & Colour & B.F.O.M (\%, maximum) \\
\hline Grade I & White to Amber & 0.5 \\
\hline Grade II & Reddish to Tan & 1.5 \\
\hline Grade III & Brown to Black & 3.0 \\
\hline
\end{tabular}

The specifications for food grade Gum Karaya are available in Indian Standards IS: 12408:1988.The Water Soluble Gums association (WSGA) grades of Gum Karaya are presented in table 2 [6].

Table 2: WSGA grades of Gum Karaya

\begin{tabular}{|c|c|c|c|}
\hline Grade & $\begin{array}{c}\text { Bark and } \\
\text { foreign organic } \\
\text { matter }(\%)\end{array}$ & Colour & $\begin{array}{c}\text { Material } \\
\text { minus 10 } \\
\text { mesh (\%) }\end{array}$ \\
\hline WSGANo.1 & $0.5(\max )$ & $\begin{array}{c}\text { White with slightly } \\
\text { gray cast }\end{array}$ & 2 \\
\hline WSGA No.2 & $1.5(\max )$ & Very light tan & 3 \\
\hline WSGA No.3 & 3.0 & Tan & 3 \\
\hline Technical sifting & 6.0 & Brown & - \\
\hline
\end{tabular}

Karaya Gum in the dry state is not soluble in water but only forms viscous suspensions. The gum enormously swells in water and forms thick suspensions. Viscosity and swelling factor play a key role in the utilization of gum for various purposes.

At the processor level the raw dried gum is further dried to about 16 to $20 \%$ moisture. Then it is quickly processed by removing impurities and broken into pieces of different sizes and grades according to the buyers' requirement of end use.

Karaya gum finds major application in bulk laxatives, denture adhesives, colostomy appliances and in appetite suppressants. Viscosity and swelling ability of the gum decides the quality of gum in industrial applications. There are applications of importance other than those mentioned above like food additives and ice cream stabilisers. A substantial quantity of the gum is exported from India while only a small percentage is indigenously used.

Gum Karaya is a safe food additive. The Joint Expert Committee on Food Additives (JECFA) of the FAO/ WHO (WHO, 1989) had reviewed and prepared a monograph based on which the JECFA has proposed "ADI Not specified". This means on the basis of chemical, biochemical, toxicological and other relevant data, the total daily intake of the substance, arising from its use at the levels necessary to achieve the desired effect and from its acceptable background in food, does

Volume 5 Issue 7, July 2016 www.ijsr.net 


\section{International Journal of Science and Research (IJSR) \\ ISSN (Online): 2319-7064 \\ Index Copernicus Value (2013): 6.14 | Impact Factor (2015): 6.391}

not, in the opinion of the committee, represent a hazard to health. (WHO, 1989) [5]. The present study is focused on viscosity studies of Gum Karaya from different sources and different periods of storage. This study helps the trade in understanding the quality aspects of gum and deciding the time of purchase for proper application of the gum.

\section{Chemicals/materials/equipment required:}

1) Distilled water still

2) Standard sieves BSS 8 and BSS 30

3) Remi high speed stirrer

4) Brookfield viscometer model RVT

5) Thermometer

6) Refrigerator

7) Electrical single pan balance sensitivity $0.1 \mathrm{mg}$

8) Spatulas

9) Plastic beakers $1000 \mathrm{ml}$

10) Laboratory grinder

\section{Methods}

\subsection{Viscosity of Gum Karaya:}

- With the help of a grinder the sample of Gum Karaya is crushed gently avoiding excess heat.

- The sample is sieved and the material between 8 and 30 mesh is taken for viscosity.

- 7 grams of sample is accurately weighed on an electrical single pan balance.

- $693 \mathrm{ml}$ water (distilled water) is stirred under a mechanical stirrer with an approximate speed of 1200 R.P.M.

- The sample is slowly added to the water under agitation in a span of about 2 minutes.

- The stirring is continued at 2000-2200 R.P.M for a period of 7 minutes.

- The material is taken out from the stirrer and kept aside for 24 hours.

- After 24 hours the material is stirred at about 2000-2200 R.P.M for 7 minutes.

- The bubbles are allowed to surface out in about 5-8 minutes.

- The temperature is adjusted to $25 \pm 2^{\circ} \mathrm{C}$ by cooling in a refrigerator.

- The viscosity is checked using Brookfield viscometer model RVT at 20 RPM using spindle No.3.

- The reading is multiplied with the factor to get viscosity in centipoises (cps).

- Where needed the spindle, speed combinations are changed according to the viscosity.

- Viscosity measurements are done on "as is" basis without moisture correction.

\section{Results and Discussions}

The studies were conducted on Gum Karaya of all the three grades classified according to the trade requirements i.e. Grade
I, Grade II and Grade III. Studies were carried out on the samples well preserved under controlled conditions at room temperature. Samples of Gum Karaya stored for one year or more at room temperature were initially taken for viscosity measurements. Viscosity results of some of the samples are presented in Table 3.

Table 3: Viscosity results of gum stored for 12 months and above

\begin{tabular}{|c|c|c|c|c|}
\hline $\begin{array}{c}\text { * Sample } \\
\text { ID }\end{array}$ & Grade & $\begin{array}{c}\text { Age of the } \\
\text { Gum } \\
\text { (months) }\end{array}$ & $\begin{array}{c}\text { Viscosity } \\
(1 \%, \text { cps })\end{array}$ & $\begin{array}{c}\text { Characteristics of the } \\
\text { suspension }\end{array}$ \\
\hline RPC-1 & I & 12 & 25 & $\begin{array}{c}\text { Particles settling with } \\
\text { almost clear supernatant. }\end{array}$ \\
\hline RPC-2 & I & 13 & 25 & $\begin{array}{c}\text { Particles settling with } \\
\text { almost clear supernatant. }\end{array}$ \\
\hline BPC-1 & I & 13 & 50 & $\begin{array}{c}\text { Particles settling with } \\
\text { almost clear supernatant. }\end{array}$ \\
\hline BPC-2 & II & 12 & 25 & $\begin{array}{c}\text { Particles settling with } \\
\text { almost clear supernatant. }\end{array}$ \\
\hline BPC-3 & II & 14 & 25 & $\begin{array}{c}\text { Particles settling with } \\
\text { almost clear supernatant. }\end{array}$ \\
\hline BPC-4 & II & 14 & 50 & $\begin{array}{c}\text { Particles settling with } \\
\text { almost clear supernatant. }\end{array}$ \\
\hline HPC-1 & III & 12 & 25 & $\begin{array}{c}\text { Particles settling with } \\
\text { almost clear supernatant. }\end{array}$ \\
\hline HPC-2 & III & 14 & 25 & $\begin{array}{c}\text { Particles settling with } \\
\text { almost clear supernatant. }\end{array}$ \\
\hline
\end{tabular}

*Sample identification number is given by our laboratory.

It is reported in literaturethat Gum Karaya loses viscosity on storage in the dry state [6].In the present study the extent of the loss and the period in which the gum loses viscosity is objectively assessed. The gum which was stored for over 12 months showed very low viscosities (as shown in Table 3) which makes the product unusable. In yet another study we found that the gum from the stocks of the first month of storage showed a viscosity above $1200 \mathrm{cps}$ [7], [8]. These results prompted us to study the viscosity of the gum month-wise from the very early stages of collection and storage. While several studies have been conducted by us on tapping, collection, storage and stability of Gum Karaya [7], [8], in this paper only the relevant results on Aging of gum vs Viscosity are presented (Table 4, 5 and 6).

Table 4: Viscosity of Gum Karaya of Grade I (Sample ref:FBPC-1)

\begin{tabular}{|c|c|c|}
\hline $\begin{array}{c}\text { Age of the } \\
\text { Gum(months) }\end{array}$ & $\begin{array}{c}\text { Viscosity } \\
(1 \%, \text { cps })\end{array}$ & Characteristics of the suspension \\
\hline 1 & 1750 & Well suspended thick gel. \\
\hline 2 & 1850 & Well suspended thick gel. \\
\hline 3 & 1800 & Well suspended thick gel. \\
\hline 4 & 1850 & Well suspended thick gel. \\
\hline 5 & 1850 & Well suspended thick gel. \\
\hline 6 & 1600 & Well suspended thick gel. \\
\hline 7 & 1050 & Thin Suspension \\
\hline 8 & 700 & Thin Suspension \\
\hline 9 & 175 & Settling of particles \\
\hline 10 & 50 & $\begin{array}{c}\text { Particles settling with almost clear } \\
\text { supernatant. }\end{array}$ \\
\hline 11 & 25 & $\begin{array}{c}\text { Particles settling with almost clear } \\
\text { supernatant. }\end{array}$ \\
\hline
\end{tabular}

Volume 5 Issue 7, July 2016 www.ijsr.net 


\section{International Journal of Science and Research (IJSR) \\ ISSN (Online): 2319-7064 \\ Index Copernicus Value (2013): 6.14 | Impact Factor (2015): 6.391}

Table 5: Viscosity of Gum Karaya of Grade II (Sample ref:FBPC-2)

\begin{tabular}{|c|c|c|}
\hline $\begin{array}{c}\text { Age of the } \\
\text { Gum(months) }\end{array}$ & Viscosity (1\%, cps) & $\begin{array}{c}\text { Characteristics of the } \\
\text { suspension }\end{array}$ \\
\hline 1 & 1350 & Well suspended thick gel. \\
\hline 2 & 1350 & Well suspended thick gel. \\
\hline 3 & 1300 & Well suspended thick gel. \\
\hline 4 & 1300 & Well suspended thick gel. \\
\hline 5 & 1350 & Well suspended thick gel. \\
\hline 6 & 1300 & Well suspended thick gel. \\
\hline 7 & 1000 & Thin Suspension \\
\hline 8 & 350 & Settling of particles \\
\hline 9 & 125 & Settling of particles \\
\hline 10 & 25 & $\begin{array}{c}\text { Particles settling with } \\
\text { almost clear supernatant. }\end{array}$ \\
\hline 11 & 25 & $\begin{array}{c}\text { Particles settling with } \\
\text { almost clear supernatant. }\end{array}$ \\
\hline
\end{tabular}

Table 6: Viscosity of Gum Karaya of Grade III (Sample ref:FBPC-3)

\begin{tabular}{|c|c|c|}
\hline $\begin{array}{c}\text { Age of the } \\
\text { Gum(months) }\end{array}$ & $\begin{array}{c}\text { Viscosity } \\
(1 \%, \text { cps })\end{array}$ & Characteristics of the suspension \\
\hline 1 & 1200 & Well suspended thick gel. \\
\hline 2 & 1250 & Well suspended thick gel. \\
\hline 3 & 1200 & Well suspended thick gel. \\
\hline 4 & 1100 & Well suspended thick gel. \\
\hline 5 & 1200 & Well suspended thick gel. \\
\hline 6 & 1000 & Thin Suspension \\
\hline 7 & 800 & Thin Suspension \\
\hline 8 & 650 & Settling of particles \\
\hline 9 & 100 & $\begin{array}{c}\text { Particles settling with almost clear } \\
\text { supernatant. }\end{array}$ \\
\hline 10 & 25 & $\begin{array}{c}\text { Particles settling with almost clear } \\
\text { supernatant. }\end{array}$ \\
\hline 11 & 25 & $\begin{array}{c}\text { Particles settling with almost clear } \\
\text { supernatant. }\end{array}$ \\
\hline
\end{tabular}

It may be observed that in some cases there is a marginal increase in viscosity (of about $100 \mathrm{cps}$ ) compared to previous month. This could be due to the instrumental variation of \pm $20 \%$ in measurement of viscosity of Non-Newtonian gum solutions or could be due to lump to lump variations of the gum samples.

We have carried out these experiments on several samples from different sources [7], [8] but only the above representative data on some specific samples have been presented.

It is observed that Gum Karaya loses viscosity after six to seven months of storage at room temperature with a drastic drop in viscosity in seven months. As the gum loses the viscosity it is observed that the aceticacid odour becomes more prominent.

The Gum Karaya lumps did not show any significant variation in moisture levels which confirms that the loss in viscosity is not due to moisture absorption or moisture variations.
This study is of significant value for the Gum Karaya trade to decide the purchase time from the time of procurement.

\section{Conclusions and Further Research}

It is well known that Gum Karaya is a perishable item. The viscosity of the gum is a very important factor for its applications. This paper is a result of specific study of the viscosity of Gum Karaya and the stability from the time of procurement. Under normal conditions of storage, it is proved that Gum Karaya shall be stable for only six to seven months from time of procurement. The product should be utilized within this period for best results. Further research has been carried out on the swelling abilities and improving the stability of Gum Karaya the document of which is in preparation at the time of writing this paper.

\section{Acknowledgements}

The authors thank various gum exporters and organisations for offering free samples for the studies. We express our gratitude to Mr.S.Bhaskar for experimental assistance and also Mrs. T.Sushuma for her help and assistance in the preparation of this paper.

\section{References}

[1] Core EL Plant taxonomy Prentice Hall, Inc, USA pp.358, 1955

[2] Thonner Fr The Flowering plants of Africa, Dulan \& Co Ltd., London pp.354, 1915

[3] Chopra RN, Nayar SL \& Chopra IC Glossary of Indian Medicinal Plants, Council of Sci \& Ind Res, New Delhi pp.234, 1956

[4] Krishnamurthy T Minor Forest Products of India, Oxford \& IBH Publishing Co. Pvt.Ltd, 1993

[5] Gautami S \& Ramesh V. Bhat, A monograph on Gum Karaya, National Institute of Nutrition, Hyderabad, 1992

[6] Arthur M. Goldstein \& Emil N. Alter "Gum Karaya", Industrial Gums, Polysaccharides and their derivatives, Whistler RL \& Be Miller JN, Academic Press, NY , London, 1973

[7] Aasha Kapur Mehta Sustainable interventions for poverty alleviation - A best practice case of Gum Karaya in Andhra Pradesh, India, United Nations Development Fund For Women (UNIFEM), New Delhi 1998

[8] Rao V. Malladi, Unpublished observations.

\section{Author Profile}

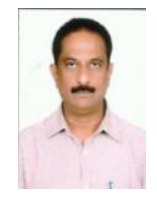

Dr.Rao V. Malladi, received M.Sc (Biochemistry) in 1975 and Ph.D (Pharmaceutical Sciences) in 1980 from Andhra University, Waltair. His main area of work for Ph.D had been Chemistry and applications of polysaccharide gums. He has over 35 years of experience in Quality control, Quality assurance and R\&D in natural gums, pharmaceutical formulations, cellulose products, herbals and spices. He is the founder and CEO of Dr.Rao's Laboratories, 


\section{International Journal of Science and Research (IJSR) \\ ISSN (Online): 2319-7064 \\ Index Copernicus Value (2013): 6.14 | Impact Factor (2015): 6.391}

Vijayawada and currently engaged in research and training on sustainable practices of farming.

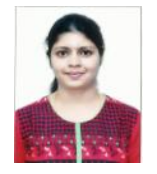

A. Radha Gayathri, received B.Pharm and M.Pharm degrees from Shri Vishnu College of Pharmacy and Gokaraju Rangaraju College of Pharmacy respectively. During her Masters she worked as an intern at Indian Institute of Chemical Technology (IICT). During that time she did her thesis work on Dried Blood Spots (DBS). She is currently working at Dr. Rao's Laboratories as a Research Assistant.

Volume 5 Issue 7, July 2016 www.ijsr.net 